\title{
THE USE OF FILMS IN TEACHING ENGLISH AS A SECOND LANGUAGE
}

\author{
H. Joan Morley and Mary S. Lawrence \\ University of Michigan
}

[ This is the third of a three-part report on the development of a program at the English Language Institute which uses documentary films for the improvement of aural comprehension, speaking, writing, and reading in English as a second language. Part I was a general description of the program; Part II was a discussion of the writing aspects of the program; the first two parts appeared in Language Learning, Volume 21, Number 1 (June 1971) pp. 117-135; Part III is a discussion of the treatment of aural comprehension in the program.]

\section{PART III:}

\section{USING FILMS IN LISTENING/SPEAKING CLASSES}

\author{
H. Joan Morley ${ }^{1}$
}

A number of textbooks designed to improve language skill in reading and writing at the intermediate and advanced levels are available to the teacher of English as a second language. A few books can be found to guide the teaching of speaking skills. However, even a cursory examination of TESL teaching materials quickly reveals a surprising paucity of materials in the skill area of listening-particularly at the intermediate and advanced levels. Although a variety of materials can be found in the areas of auditory discrimination and aural grammar practice, few go beyond rudimentary listening. They concentrate only on fragments within the listening process. They stop short of the real goals of aural comprehension training-listening for facts and ideas-listening to analyze and evaluate-listening as an integral part of the communication process.

IThe author wishes to thank the staff and students of the English Language Institute for their help in the development of the program reported here. Twenty-eight teachers and over four hundred students have participated. Special thanks also to Paul Munsell and Sharon Spencer for trial use of the materials at Michigan State University. 
It is difficult to cite the reasons for this almost total neglect of listening, one of the most essential of the four language skills. Perhaps a lack of clarity in defining some of the nomenclature used to describe various aspects of listening-aural-oral method, auditory discrimination, aural grammar, aural comprehension, listening skill-has clouded the issue and created a false feeling of having accomplished the entire task. Perhaps an assumption that listening is a reflex, a little like breathing-listening seldom receives overt teaching attention in one's native language-has masked the importance and complexity of listening with understanding in a non-native language. Or, perhaps the difficulty of attacking the many problems of attempting to teach this high-level aural-cognitive skill, of breaking it down into manageable classroom presentation, has been too formidable.. In any case, little published material exists which is designed to move a student step by step along a continuum from identification of sounds and sentence patterns, at the lower end, to the complexities of coping with rapid aural-intellectual processing of facts, ideas, inferences, and judgments, at the upper end.

Whatever the reasons, teachers have been forced to improvise and to adapt materials intended for other uses. Often the effect has been to bombard the intermediate and advanced student with masses of random aural material assuming that something magical would take place. Specific purposes, long-range objectives, and progression of difficulty have been lacking.

During three years of preparation of teaching materials at several levels along the listening continuum (Morley 1972), a film program for advanced and intermediate students has been developed. It is an important part of the total Aural Comprehension Program being designed to help students cope with progressively more sophisticated listening situations. Use of this audio-visual medium in actual structured classroom sessions has proved a profitable multimodality teaching tool for realistic language practice. And it has proved an intellectually challenging and motivating experience for students and teachers alike.

However, a successful program implies thoughtful film choice, thorough exercise preparation, careful classroom presentation, and a philosophy that a film program is a bonafide teaching tool. Use of films for fun, diversion, or rainy-Friday-afternoon-filler is not implied in this concept of "film program." Just as a book of reading selections is chosen with careful attention to the level of difficulty, suitability of subject matter, and quality of the readings and exercises, so the selection and preparation of a book of films must be approached in the same way. Failure to do so can result 
not only in wasted time but in discouraged, uninterested, and apathetic students.

Criteria for Constructing Aural Comprehension Lessons 2

The six following criteria have been established to guide the construction of lessons for the comprehensive Aural Comprehension Program. They help insure carefully planned and carefully graded lessons whether simple basic listening tasks or complex sophisticated listening tasks. In fact, of course, most of the criteria can apply to teaching materials under development in any of the language skill areas.

(1) No lesson should be written without definite goals and subgoals all of which fit into a total framework of the distinctive kinds of listening. The integrants of listening are difficult to separate. However, for practical planning it is possible to delineate some distinct areas or types of listening tasks, albeit they are overlapping and cumulative: in the realm of "receptive" listening, (a) rudimentary perception and reception with recognition of basic sound, prosodic, and syntactic patterns (encompasses auditory discrimination and aural grammar), and (b) listening to get factual information (often with the goal of immediate recall); in the realm of "reflective" listening, (a) listening to get ideas (understanding interrelationships), (b) listening to make intellectual judgments (including synthesis, analysis, evaluation, etc.), and (c) listening to enjoy (making aesthetic judgments.) Students as well as teachers should be aware of these goals.

(2) Each lesson should require active overt participation on the part of the student-not passive detachment. One way this can be accomplished in listening lessons is by requiring some kind of immediate written response. In addition, giving students immediate (or only slightly delayed) feedback about their performance is a positive factor in securing active student interest and involvement.

(3) Each lesson should be structured so that students know exactly what to listen for, where to listen, and how to listen. Structure is essential in order to reduce the anxiety which many students have about aural comprehension. Many are afraid they won't understand, afraid of forgetting, defeated because of past failures in "catching" the meaning of what is said to them. Structured material gives them security, delimited manageable tasks, a chance to "catch" a little at a time, and gradually build to a point where they can handle increasingly sophisticated language situations.

$2 \mathrm{~A}$ complete discussion of this section was presented at the ATESL section meeting of NAFSA-Region V Conference in Chicago in November, 1971 under the title "Improving Aural Comprehension: Some Practical Suggestions for Classroom and Laboratory." 
(4) All lessons should guide students toward disciplined listening-self-disciplined concentration on the task. Psychologists who specialize in memory cite two key factors essential to listening and remembering. One is concentration and the other is degree of urgency for remembering. In our native languages most of us are not very well-disciplined listeners. Whatever discipline we do exercise is in direct proportion to concentration and urgency. Fortunately, language redundancy-set as high as $50 \%$ by some investigators-affords native speakers the luxury of relaxed listening. Unfortunately, the various cues which constitute redundancy are just the bits and pieces which are difficult for the second language learner to assimilate-a minutia of sound and prosodic features, morphological and syntactic structures which reinforce and overlap, context clues, cultural overtones, predictability of certain things in certain places, limited selection and co-occurance restrictionsall of which assist each other in the deciphering of the transmitted message.

Encouraging and guiding the student to develop disciplined listening habits is one way to help him compensate, and so better cope. It also has a value in fending off the defeatist attitude often used as a defense mechanism, "I don't (or I can't) understand. Please repeat." which sometimes actually seems to be saying, "I won't." Structured materials which demand disciplined listening also can be valuable in capturing and keeping the attention of some of the more volatile, exhuberant students who find concentration somewhat out of character-perhaps, in some instances, out of cultural character.

(5) All lessons should stress conscious memory work with special attention to lengthening memory span and strengthening immediate recall. Hearing is perceiving, while listening is receiving, receiving requires thinking, and thinking requires memory; there is no way to separate listening, thinking, remembering. Listening is thinking-and thinking is remembering.

Because the spoken utterance is so ephemeral in the temporal dimension-it's here-and it's gone-,because the interpretation of language is on a cyclic not a. linear basis, the basic psycho-physical intervention in the resolution of decoding linguistic messages. is reauditorization. Sometimes it is conscious; most often it is not. Neuropsychologists tell us that reauditorizing strengthens the memory trace through a bio-chemical process. We cannot teach reauditorization per se, but we can teach conscious attention to remembering and conscious repeating of material in one's mind.

(6) Lessons should teach not test. Although questions are used to help students assess their level of comprehension, they should 
not be viewed with a pass/fail connotation but only as a tool necessary in monitoring performance. Obviously, it is the responsibility of the teacher to provide work which is just challenging enough to move the student along but not so difficult that it is defeating.

\section{The Film Program}

The listening/speaking/vocabulary-building film program described here and in Morley and Lawrence (1971) is designedfor advanced and high-intermediate ESL students. (Construction of a high-beginning and low-intermediate film program is underway and will be reported at a later time.) Criteria for film selection are determined by the two purposes which underlie the film program. One purpose is linguistic-to provide students with realistic listening/ speaking practice with emphasis on aural comprehension, fluency in speaking, pronunciation, and vocabulary building. The other purpose is informational-to provide students with up-to-date, relevant information about contemporary affairs.

The six specific criteria followed in selecting films are: (1) relevance and timeliness in personal-social, national, and/or international issues of the day; (2) a thread of continuity which ties a series of films together; (3) technical quality of the film; (4) voice, intelligibility, and dialect factors; (5) variety in the organizational and illustrative methods used in the films; (6) manageable amount of new vocabulary items. See Morley and Lawrence (1971:121-123) for more complete explanations of criteria.

To introduce the film program to the students they are provided with a one-page sheet which explains purposes of the program and lists the films included in the program. (See Morley and Lawrence (1971:121) for the list of films). It is suggested that the teacher read the explanatory sheet aloud and discuss it with the students.

In introducing the program to teachers, five points are stressed.

(1) Each of the ten films in the series has a 10-12 page student work-book which contains six Listening/Speaking (L/S) assignments. Each assignment has been prepared carefully to give the students maximum help toward the three stated language goals, Listening/ Speaking/Vocabulary Buïlding. ${ }^{3}$

(2) The intent of the $\mathrm{L} / \mathrm{S} /$ assignments is to "teach not test." The first consideration here is to be sure students receive very thorough preparation for the film. Students consistently report that the better they are prepared, the more they get from a film. Responsibility for thorough preparation rests equally with the student

\footnotetext{
3The assignments are: \#1 - Aural Comprehension Study Guide, \#2 - Key Vocabulary for Oral Practice and Discussion, \#3 - Main Ideas, \#4A - Specific Facts: Question Guide and Fact Sheet OR \#4B - Specific Facts: Analysis, \#5 - Personal Opinion: Discussion Topics, and \#6 - Aural Comprehension Test. These assignments will, be described in detail in this article.
} 
and the teacher. It is the student's responsibility to do the assigned homework to the best of his ability; it is the teacher's responsibility to read, discuss, and practice $\mathrm{L} / \mathrm{S}$ assignments \#1 and \#2 as the workbook directs. A second consideration of "teach not test" is to be sure the questions in L/S assignments \#3, \#4A, $\# 4 \mathrm{~B}$, and \#5 are used to provide a common ground for class discussion and/or expressions of personal opinion, not to test aural comprehension, with a pass/fail connotation. Students should be encouraged to answer as well as they can and not to feel embarassed if they are not correct; learning from each other during class discussion is another facet of practicing aural comprehension. Assignment \#6 is the only one which might be used for testing. However, teachers who do not feel compelled to "test" can use assignment \#6 profitably as alternative basis for class discussion following a second (or third) showing of the film.

(3) The program is planned with the intention of double, even triple, showings of the same film, probably on different days. The multiple showing notion is not designed to entertain; it is planned to give the students a chance to "re-listen" in much the same way they re-read material-to get more out of it, and to reinforce vocabulary. Each showing should have a specific and slightly different listening focus which is guided by the pre-assignment of the questions in one of the last four $\mathrm{L} / \mathrm{S}$ assignments. No student should be allowed to watch a film without a pre-assigned listening focus. It may be simple ("At the end of the showing write the most important message of the film,"); It may be elaborate ("Take as complete a set of notes as you can as you watch the film").

(4) As indicated earlier, psychologists who specialize in listening and remembering cite two key factors essential to memorydegree of urgency for remembering and concentration. The "urgency" is provided for here by the pre-assigned listening focus to which the student must respond with an overt (written) answer. The thorough preparation is one step toward encouraging "concentration." A second step is to stress concentration verbally and to encourage a good "psychological set" for disciplined listening by keeping distractions to a minimum and, Victorian as it may sound, by "setting a good example"-sitting with the students and doing precisely what they have been asked to do.

(5) No one class will use all six of the L/S assignments, although all should use assignments $\# 1$ and \#2 and probably \#3 (higher classes in a less formal way, perhaps.) Low advanced and high intermediate classes will probably want to emphasize the more concrete facts and ideas from the film. (See L/S assignments \#4A and \#6.) High advanced classes probably will want to concentrate 
on only a brief resume of the facts and ideas, moving quickly to identifying some of the methods used in the organizational framework of the film, then concentrating on the inferences and implications of the film. (See L/S assignments \#4B and \#5.)

The amount of time spent on any film will probably vary. The level of the class, the interest value of the film, and the attention to other L/S work will be deciding factors. Each teacher should choose and adapt assignments to fit the needs of the class and the amount of time available.

Assignment \#1: Aural Comprehension Study Guide. (For a sample of this assignment see Morley and Lawrence (1971:131). The purpose of this assignment is to guide students in what to listen for and how to find the organizational plan and illustrative methods used in the film in order to prepare for fullest auditory comprehension. In reading and discussing the study guide, students can be encouraged to speculate about what they can expect to see in the film. Also, they can be asked to comment about items from their own personal knowledge or experience. The more the student becomes personally "involved" during this preparatory session, the better he is motivated to concentrate when viewing the film. Assignment \#2: Key Vocabulary for Oral Practice and Discussion. (See Morley and Lawrence (1971:130) for a sample of this assignment.). The purpose of the vocabulary work at this point in the film lesson is two-fold: (1) to introduce items (the students' actual 'learning' of new vocabulary will come about as they see the film several times, answer questions, and discuss), (2) to give students aural andoral experience with both familiar and unfamiliar items. "Key" vocabulary does not necessarily mean new vocabulary. The intent of the vocabulary assignment is to focus student attention on nucleus vocabulary items-old words and phrases as well as new ones-and to provide practice in hearing and pronouncing them.

It is essential that the in-class oral practice with the vocabulary not be neglected, for two reasons: (1) The listening/speaking skills are very closely related. The student's oral experience of pronouncing phrases and words with the resultant moto-kinesthetic as well as auditory stimulation can be an important aid to his recognition of the words and phrases the next time he hears them. (2) As a student reads a vocabulary word silently from the list, he may imagine-or actually produce-a pronunciation which is wrong, due to his own faulty pronunciation, as in, for example, "famine" (famin) and "jeopardy" (jiopardi). If, then, he expects to hear that pronunciation in the film, he will miss the word when it is spoken in its correctly pronounced form. 
Students are encouraged to keep the vocabulary list, which is arranged in order of first appearance, in front of them for refference as they watch and listen to the film. A small amount of dim light during a filming does not seem to interfere with either student concentration or aesthetic appreciation.

Assignment \#3: Main Ideas. The purpose of this assignment is to help students concentrate on an overall perspective and identification of essential main ideas. Students are given the following directions: "Please answer each question immediately after you have seen the film for the first time. Be prepared to present and to defend your answers during class discussion." Thus the student is asked to do a second thing during the first showing. First, he was asked to follow the vocabulary list as he listens. Now, in addition, he is asked to attend consciously to the main ideas presented.

The answers quoted below are verbatim quotations from student papers. They serve as a common core for class discussion; they provide structure and direction; they are sufficiently general to allow almost every student to be at least partially right. A student is encouraged to express any opinion as long as he is willing to try to defend it with reasonable argument; no answer is ruled as "wrong," unless a good reason can be given.

Initially several students are asked to present their answers to a given question. Others are asked to agree, disagree, and challenge. Then the original students are allowed to respond. Often. answers are written on the blackboard and examined critically for clarity and exactness of answer in response to precise inquiry of the question.

The give-and-take of the situation enables even the shy students to be drawn into the discussion. Sometimes a student leader is chosen to guide the discussion and to encourage participation from all. The length of the discussion may vary from a few minutes to half an hour depending upon the interest value of the film and the disparity of the answers.

Assignment \#3 asks the same three questions for each film. Through the series of films the intent is to sharpen the student's ability to focus on key ideas and to improve his ability to think critically in English. Selected answers to the three questions on the film Problems of Conservation: Air 4 are quoted below; they were taken directly from student books. (Spelling errors and some grammatical errors have been corrected.) Notice the disparity in answers; some are too broad and some are too narrow; others do

4Distributed by Encyclopedia Britannica Educational Films. 15 minutes - color. 
not answer the questions with precision. The subsequent discussion and analysis of words and ideas was lively and constructively critical.

Question 1: What was the subject matter of the film? (4 or 5 words)

Student A - Effects of air pollution.

Student B - Pollution.

Student C - The cause of air pollution in big cities.

Student D - Problems of air pollution and how to solve them.

Student $\mathrm{E}$ - The contaminants of the air and results of air pollution.

Student F - The danger of air pollution.

Student G - How to solve air pollution.

Student H - Many problems occur because of air pollution.

Student I - Air pollution, how it is produced and how it can be avoided.

Question 2: What was the most important message of the film?

Student A - Air is being polluted and we must try to prevent it. Student B - There are no overnight solutions.

Student C - Air pollution contains many dangerous things and gases that can kill lives.

Student D - Air pollution is a serious problem.

Student E - We should control air pollution.

Student F - He tried to convince us that air pollution is going to be an important matter and we should try to conserve air; as it has been done in America.

Question 3: Many students think the title, Problems of Conservation: Air is a poor name for the film. Think up a new title for the film and tell why you chose it.

Student A - Diseases Caused by Dirty Air and The Avoiding Points (because it concerns the most part of the film.)

Student B - Can Clean Air Get Along with Industries? (Co-Exist) (because conserving clean air is a challenging problem because useful industries cause part of air pollution.)

Student C - How to Solve Air Pollution (because we have realized the necessity for it although we don't know how.)

Student D - Air Pollution (because the film concerned mostly with air pollution.)

Assignment \#4A: Specific Facts: Question Guide and Fact Sheet. (See Morley and Lawrence 1971:133). The purpose of this assignment is to focus the students' attention on specific facts through an ordered set of questions designed to extract key factual information. Questions in the assignment are discussed before the 
second showing of the film. This is designed as a follow-up assignment for the low advanced and high intermediate levels. The emphasis is on the more concrete facts and ideas. Students should write answers and discuss.

Assignment \#4B: Specific Facts: Analysis. The purpose of this assignment is to focus on specific facts and again emphasizes organizational and illustrative methods. The following directions are given: "Read each question carefully. Take notes during the showing of the film. After the showing write short answers. The words in capital letters emphasize methods used in organizing information and illustrating facts and ideas. If you do not understand them, consult your dictionary or ask your teacher for help."

This is designed as a brief follow-up for higher advanced classes. It is often assigned in conjunction with Assignment \#5.)

SAMPLE: Specific Facts: Analysis Sheet from Meanings are in People. 5

1. Misunderstanding of the words "burn it" occurred because it is an ambiguous term. EXPLAIN the two interpretations of term.

2. Frank, the manager, and George, his employee had an argument because of a communication breakdown. Later Frank expressed three personal feelings CAUSED BY the communication breakdown. List those three feelings.

3. CONTRAST the two points of view which these statements represent:

(a) "That's not what I said." (Meanings are in words.)

(b) "That's not what I meant to say." (Meanings are in people.)

4. Give another EXAMPLE of communication breakdown as shown in the film.

5. Give one of the NEGATIVE DEFINITIONS given in the film.

Assignment \#5: Personal Opinion: Discussion Topics. Morley and Lawrence (1971:134) for a sample of this assignment.) The purpose of this assignment is to provoke discussion and expressions of personal opinion-in small-group work-in general class discussion-in short (5-minute) individual speeches-in formal or informal debate. Higher level students seem to enjoy this assignment the most. Small-group work has been popular with many

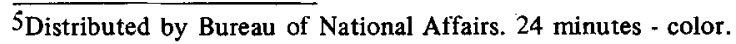


teachers. Some are highly structured with a chairman who sees that everyone participates, a secretary who must report findings to the whole group, and one or two questions or problems to which the students must address themselves. Classroom debates with some students playing the "devil's advocate" and defending an unpopular side of an issue have been developed by some teachers. ${ }^{6}$ Sometimes questions from Assignment \#6 also are used for class discussions; sometimes teachers or students add their own questions or problems for study.

SAMPLE: Personal Opinion: Discussion Topics from Conquering the sea. 7

1. Some people believe the resources of the sea will provide the solution to the world food problem. How realistic is this idea? Consider cost, distribution, and other problems.

2. At the present time what specific resources from the sea are being used in your country?

3. Discuss the problems of "ocean pollution" which will be the result of many of the examples given in the film.

4. Jacques Cousteau is one of the foremost underwater explorers. Perhaps class members can describe some of his explorations.

5. Choose one point or idea from the film with which you strongly agree/disagree and give your reasons.

6. Choose one point or idea from the film and compare/contrast other information (supporting/conflicting) which you have heard or read about it.

Assignment \#6: Aural Comprehension Questions. "(See Morley and Lawrence (1971:135) for a sample set of test questions.) The purpose here is to test comprehension (although the questions might be used less formally for class discussion.) As has been suggested earlier, this assignment may be used in several waysfollowing Assignment 4A for the lower levels as a basis for controlled class discussion-following Assignment 5 for the upper levels as a source of personal opinion discussion topics-or as a "real" pass/fail test assignment.

\footnotetext{
6Teachers Marjorie Baril, Helen Carney, Carol Compton, and Dorothy Messerschmidt have developed structured buzz sessions and debates.

7Produced by CBS News. Distributed by McGraw-Hill, 25 minutes - color.
} 
Conclusion

This kind of program provides an opportunity for students to participate in purposeful language learning, language for communication of thoughts and ideas, language in a setting which provides real communicative urgency. At the same time it has structure, direction, and purpose. It is designed to move the student ahead in his listening/speaking abilities.

This kind of program involves the student in his own learning process. The purposes and directions are in the student's book, not a teacher's manual. The burden of responsibility rests with the student, to prepare and to participate. He cannot play a passive role; he is forced to play an active role.

Lastly, this kind of program provides high-intermediate and advanced students with realistic sophisticated listening/speaking opportunities at the upper level of a comprehensive aural comprehension program.

\section{RE FERENCES}

Morley, H. Joan. 1972. Improving Aural Comprehension - Student's Workbook and Teacher's Book of Readings. The University of Michigan Press, in press.

Morley, H. Joan, and Lawrence, Mary S. 1971. The use of films in teaching English as a second language. Language Learning $21: 1$. 117-135. 